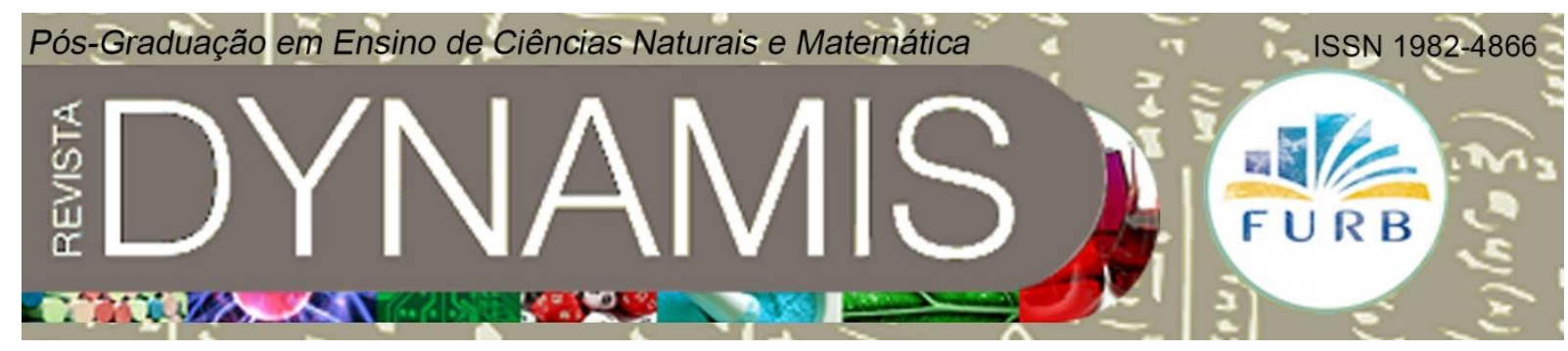

\title{
ATIVIDADES DE ENSINO REALIZADAS NO MUSEU DE HISTÓRIA DO PANTANAL/MUHPAN E QUESTÕES INDÍGENAS
}

Teaching activities done in the Museu de História do Pantanal/MUHPAN and indigenous issues

Ketylen Karyne Santos da Silva

Mestranda do Programa de Pós-graduação em Educação

Bolsista CAPES

Universidade Federal de Mato Grosso do Sul - Campus do Pantanal

ketylenk@hotmail.com

Josiane Peres Gonçalves

Doutora em Educação

Professora do Programa de Pós-graduação em Educação

Universidade Federal de Mato Grosso do Sul - Campus do Pantanal (UFMS/CPAN)

Programa de Pós-Graduação em Educação do Centro de Ciências Humanas e Sociais (UFMS/CCHS) Universidade Federal de Mato Grosso do Sul

josianeperes7@hotmail.com 


\title{
Resumo
}

Diante da importância dos museus para a sociedade, caracterizados por espaços em que se concretiza a educação não formal, o presente estudo aborda essa temática com o propósito de refletir sobre as atividades educativas realizadas pelo Museu de História do Pantanal/ Muhpan, com ênfase para as atividades de ensino e cultura indígena. Assim, inicialmente são apresentadas discussões relativas às funções sociais dos museus e o que se entende por educação não-formal. Em seguida apresenta-se o histórico do Muhpan, como encontra-se organizado o seu circuito expositivo, com ênfase para informações sobre cultura indígena e atividades educativas realizadas pelo referido museu. Os resultados sugerem que o Muhpan deve ser visto como um portador de estratégias discursivas, transmissor de um conhecimento geral e não aprofundado da história indígena, porém o conhecimento transmitido no referido museu é capaz de servir de referência para a construção de novos saberes. Dessa forma, compreendemos que o Muhpan apresenta conhecimentos e contribui com o processo de transmissão de valores, mas é preciso haver um mediador ou professor orientador, que dirija a visita e não se deixe ser influenciado pelo discurso do senso comum.

Palavras chave: Museu. Indígena. Pantanal.

\begin{abstract}
In view of the importance of museums to society, characterized by spaces in which non-formal education is concretized, the present study addresses this theme with the purpose of reflecting on the educational activities carried out by the Museu de História do Pantanal/ Muhpan, with emphasis on Teaching activities and indigenous culture. Thus, discussions about the social functions of museums and what is meant by non-formal education are initially presented. Then the history of Muhpan is presented, as its exhibition circuit is organized, with emphasis on information on indigenous culture and educational activities carried out by the museum. The results suggest that the Muhpan should be seen as a carrier of discursive strategies, transmitting a general and unfounded knowledge of indigenous history, but the knowledge transmitted in the museum is capable of serving as a reference for the construction of new knowledge. In this way, we understand that the Muhpan presents knowledge and contributes to the process of value transmission, but there needs to be a mediator or guiding teacher who directs the visit and does not allow himself to be influenced by the discourse of common sense.
\end{abstract}

Keywords: Museum. Indigenous. Pantanal. 


\section{INTRODUÇÃO}

Se tentarmos estabelecer relações entre museu, ensino e cultura indígena no contexto do século XVIII, por exemplo, poderíamos perceber que as temáticas indígenas nunca seriam retratadas dentro de um museu, assim como práticas educativas não fariam parte das ações museológicas. No referido período histórico, os museus eram elitistas, restritos a determinada camada social e somente se preocupava em expor objetos, conforme Martins (1999). Gradativamente os museus foram passando por modificações e na atualidade é possível haver práticas de ensino e representação de culturas indígenas, bem como de diversas outras culturas existentes no Brasil.

Diante de tal constatação, e considerando o contexto do Museu de História do Pantanal/ Muhpan, localizado no centro de Corumbá MS e inaugurado em 2008, que é aberto a todos os públicos, cabe questionar: Como o referido museu ensina a história e cultura indígena para seus visitantes? Quais atividades de ensino são mais frequentemente realizadas pelo Muhpan? Para tentar encontrar respostas para tais indagações é que se justifica a realização do presente estudo, que tem por finalidade refletir sobre as atividades educativas realizadas pelo Muhpan, com ênfase para as atividades de ensino e cultura indígena.

Para o desenvolvimento do estudo, são utilizados os seguintes encaminhamentos: a) Pesquisa bibliográfica sobre museus, educação não formal e organização do Museu Histórico do Pantanal, incluindo práticas educativas desenvolvidas e como são apresentadas as culturas indígenas no museu; b) Análise de desenhos feitos por alunos dos anos iniciais do ensino fundamental, com idade entre 9 e 11 anos, após a visita ao Muhpan, para entender qual conhecimento predomina entre os estudantes após a visitação.

Nesse contexto, o estudo encontra-se assim organizado: Após a introdução, a abordagem teórica retrata a história dos museus e suas transformações com o decorrer dos anos. Em seguida, haverá uma discussão sobre o conceito de educação em espaço não-formal. $\mathrm{Na}$ continuidade, haverá a apresentação da história do Museu de História do Pantanal, além da organização do espaço do Muhpan e questões indígenas. E por último serão apresentadas as práticas educativas sobre as questões indígenas.

\section{MUSEUS: EVOLUÇÃO E FUNÇÃO SOCIAL}

Os espaços museológicos existentes atualmente são frutos de um processo de transformação. Suas origens estão ligadas a Grécia Antiga, aos Mouseion ${ }^{1}$, locais que eram reservados para contemplar e realizar estudos. No decorrer do tempo, esses espaços foram ganhando novos significados e na Idade Média este conceito foi pouco utilizado. No século $\mathrm{XV}$, à luz do período Renascentista e das grandes navegações marítimas, o ato de colecionar se tornou moda na Europa e muitas dessas coleções que foram se formando se tornaram museus, espaços semelhantes aos que conhecemos atualmente. Porém, por mais que esses locais tivessem semelhança aos museus da atualidade, eles ainda eram restritos a determinada camada social, os mais abastados (JULIÃO, 2001).

No Brasil a Revolução Francesa influenciou na inconfidência Mineira e também na criação do primeiro museu, chamado de Museu Real, o qual tinha o objetivo de exaltar a

\footnotetext{
${ }^{1}$ Mouseion denominava o templo das nove musas, ligadas a diferentes ramos das artes e das ciências, filhas de Zeus com Mnemosine, divindade da Memória.
} 
nobreza. Posteriormente muitos outros museus foram sendo criados no país. Com a independência do Brasil, o Instituto Histórico e Geográfico Brasileiro (IHGB) foi uma instituição responsável pela pesquisa e criação da História nacional. Pois o Brasil não possuía uma História "oficial" e sim várias histórias. Era necessário criar uma história nacional capaz de exaltar a elite e os grandes feitos, dos grandes heróis. O que era nacional precisava ser exaltado e os museus se transformaram em um mecanismo de transmissão dessa história nacional que exaltava a elite. E com o ideal de que todos precisavam conhecer os fatos e personagens do passado, pois até então o museu era um espaço particular.

Somente em 1968 a cultura dos povos foi contemplada com a inauguração do museu do folclore, promovendo a valorização das duas culturas: a erudita e a popular. Para Cavalcante (2000), as ações do Instituto do Patrimônio Histórico e Artístico Nacional (IPHAN) foram criticadas devido ao fato de ser elitista. Somente com a criação em 1975 do Centro Nacional de Referência Cultural (CNRC) foi promovida uma reflexão crítica e uma renovação conceitual no campo da preservação do patrimônio cultural e com essas mudanças o IPHAN passou a reconhecer a diversidade cultural dos países. Assim, os pequenos grupos passaram a ser incorporados na prática prevencionista, como produtos da cultura e sujeitos da história.

Podemos perceber que o museu passou por um processo de transformações, se atualmente ele atua de forma mais dinâmica e com ações educativas desenvolvendo atividades para todos os grupos, em seu passado se preocupou somente em expor objetos para um determinado grupo de uma determinada época. Para Carlan (2009), historicamente o museu produz conhecimento e não deve este somente guardar objetos sem realizar pesquisas. Pois caso contrário, sua função se reduz somente a expor para turistas. Para ele, a pesquisa é o coração pulsante dentro dos museus.

No contexto da história dos museus, sua primeira função estava vinculada ao ato de colecionar, os objetos eram particulares e restritos a determinada camada social. A transformação do papel dos Museus foi ocorrendo no decorrer dos tempos. Os museus assim como a educação, foram meios de manipulação da sociedade e um mecanismo de exaltar a história dos grandes heróis. Somente a partir da década de 1960 é que os museus recebem profundas críticas, devido seus métodos antidemocráticos. Aliados aos movimentos sociais que ocorriam mundialmente, os museus reformulam suas estruturas (SILVA, 2011).

Os museus evoluíram nitidamente de uma atitude meramente depositária e conservadora, em que as obras em si eram o mais importante, para outra que se poderia descrever como orientada para o público. Neste caso, seu objetivo é "[...] tanto quanto manter uma obra, criar as condições para que essa obra entre no circuito imaginário da cultura mediante sua exposição adequada ao público". (MARTINS, 1999, p. 269).

$\mathrm{Na}$ atualidade os museus desenvolvem diversas formas de atividades, além de expor. A ação educativa se tornou o coração dos museus, buscando desenvolver atividades a fim de atrair os mais variados públicos. Essas relações sociais que antes eram deixados de lado, hoje dão sentido ao espaço museal, pois são elas responsáveis por dialogar com o público, possibilitando ao público várias perspectivas de interpretação do discurso expositivo presente dentro dos museus.

Mesmo com toda a mudança nas funções dos museus, estas instituições carregam consigo opiniões e pontos de vista de determinado narrador. Ao propor-se contar uma história de um determinado período ou época, o que se tem, é a história contada a partir da perspectiva do narrador. Por isso a importância em analisar o contexto histórico transmitido dentro destes espaços educativos. 
Nessa perspectiva, é possível afirmar, conforme Silva (2011, p. 27), que “Os museus são instituições com grande responsabilidade social, já que podem ser formadores de opinião. Todo museu tem caráter pedagógico, transmitindo ideias, há um processo comunicativo. Não existe assim discurso neutro."

\section{EDUCAÇÃO EM ESPAÇO NÃO FORMAL}

Os Museus enquanto espaços de educação não formal, são atrativos ao público em geral, segundo Van-Präet e Poucet (1989), devido ao tempo, espaço e objeto. Segundo os autores, o tempo é determinado pela exposição ou pelo educador. O lugar seria um espaço aberto, onde o visitante é voluntário e geralmente cativado pela exposição. E o objeto seria fonte de riqueza e interatividade. $\mathrm{O}$ elo dos três fatores possibilita que o visitante se sinta atraído e estimulado a aprender. Studart (2003) complementa que em ambientes de educação não formal são levados em consideração os interesses do público visitante, ressaltando as interações sociais e a liberdade para realizar escolhas nesse espaço.

Ao refletir sobre a educação formal que ocorre nas escolas e a educação não formal ocorrida nos museus, Marandino (2005) destaca a questão temporal, visto que na escola o aluno tem uma presença rotineira, enquanto que no museu a visita é passageira, mas que ambos os espaços contribuem para a construção de conhecimento.

[...] tanto a escola como o museu, concorrem para a conservação e para transmissão do substrato cultural de um povo ou de uma civilização. No entanto, as duas instituições se distinguem uma da outra. Na escola, o objeto tem o papel de instruir e educar e o cliente cativo e estável, estruturado em função da idade ou da formação. Possui um programa que lhe é imposto e pode fazer diferentes interpretações, sendo, contudo, fiel a ele. É concebida para atividades em grupos (classe), com tempo de 1 ano e tais atividades são fundadas no livro e na palavra. No caso dos museus, o objeto encerra funções de recolher, conservar, estudar e expor. O cliente, por outro lado, é livre e passageiro, atendendo a todos os grupos de idade, sem distinção de formação, sendo suas atividades concebidas para os indivíduos ou para pequenos grupos. Possui exposições próprias ou itinerantes e realiza suas atividades pedagógicas em função de sua coleção e do objeto. O tempo utilizado pelo público é em geral de $1 \mathrm{~h}$ ou $2 \mathrm{~h}$ (MARANDINO, 2005, p. 3).

Ao oferecer acesso a novas linguagens, tecnologias, conhecimentos e valores, estimulando a curiosidade dos visitantes, os museus favorecem o processo de aquisição de conhecimento e cada vez mais eles têm sido valorizados pelos professores que percebem esse espaço como local para ampliar o conhecimento, ter contato com objetos da exposição de determinada época e ter uma pessoa especializada para repassar esse conhecimento utilizando uma linguagem diferente da sala de aula.

Segundo Anderson Kisiel e Storksdieck (2006), o sucesso de uma visita escolar a um espaço de educação não formal é, em grande parte, dependente das expectativas, do conhecimento prévio e, sobretudo, das atitudes dos professores em relação a tal espaço, antes e depois da visita. No entanto, é importante que o professor conheça o espaço em que levará os seus alunos, pois assim, conseguirá vincular o discente ao conteúdo expresso no museu, e com isso obter um melhor aproveitamento da visita. Pois as exposições e recursos educativos não devem ser confundidos com recurso didático utilizado dentro do âmbito escolar. Nesse sentido, Cazelli, Marandino e Stuart (2003, p. 101) ressaltam que: 
[...] museus não são escolas e mediadores não são professores. Conhecer como professores utilizam o espaço do museu e como os profissionais da área educativa desenvolvem suas atividades de mediação, identificando os saberes que estão presentes nesses processos, se constituem em um campo de investigação necessária.

Assim como os professores devem estar preparados para levar os seus alunos a uma visita ao museu, também é importante que as instituições museológicas tenham mediadores preparados para auxiliar na compreensão dos processos educativos das histórias narradas pelos museus. Como defende Marandino (2005), os educadores de museus não podem estar restritos às salas de educação. É cada vez menos sustentável a ideia de que o educador participe somente no momento de traduzir as informações já dadas e prontas, que foram elaboradas pelos especialistas. $\mathrm{O}$ trabalho interdisciplinar com todos os seus desafios epistemológicos, políticos e econômicos, se faz imprescindível no processo de comunicação e de educação que ocorre nos museus de ciências.

Nesse sentido, observa-se que as atividades educativas em museus são diversas. Uma atividade bastante utilizada é a visita orientada, por ser atrativa e motivadora, ampliando o relacionamento visitante, mediador e objeto da exposição. Neste tipo de visita, o mediador conta toda a história exposta no circuito expositivo do museu e tem a oportunidade de conhecer os visitantes, seus interesses e curiosidades, a bagagem que ele traz consigo e assim poder adaptar a visita de acordo com a realidade de cada visitante.

Os mediadores acompanham os visitantes por todo circuito expositivo dos museus, estimulando a reconstrução de um conhecimento já existente e a construção de novos saberes. Segundo Alabarse (2001), essa interação com outros indivíduos permite que se aprenda com maior facilidade. Porém, essa atitude de ter alguém para orientar o percurso, não tira a autonomia dos visitantes de explorar a exposição de forma autônoma. Ela salienta que o mediador deve ser uma pessoa especializada, que irá atuar como mediador/monitor. Massarini (2007) nos mostra a importância deste mediador, pois é ele capaz de traduzir as diferentes linguagens apresentadas nos discursos dos museus e isso aproxima o visitante da exposição.

Dessa forma, o ato de mediar significa possibilitar a emergência de novos saberes e a ampliação de significados elaborados por conta própria pelos visitantes na interação com os objetos expostos. Assim, os museus são espaços de negociação de saberes resultantes de interações entre os sujeitos e os instrumentos de comunicação (MORAES et al., 2007).

\section{MUSEU DE HISTÓRIA DO PANTANAL}

O Museu de História do Pantanal/ Muhpan está localizado na cidade de Corumbá, capital do Pantanal, no Estado do Mato Grosso do Sul. A cidade sede deste Museu é a segunda mais antiga do Estado, fundada em 21 de setembro de 1778 e foi palco de diversos acontecimentos históricos brasileiros. O Pantanal banha cerca de $60 \%$ do seu território e essa união de Pantanal e de 237 anos de existência torna Corumbá uma cidade repleta de história que é devidamente salvaguardada dentro do Museu de História do Pantanal.

O Museu inaugurado, em 12 de agosto de 2008 teve como iniciativa de criação a união conjunta entre o Ministério da Cultura e autoridades locais, os quais observaram a necessidade de instalar um museu capaz de ser um "chamariz para um turismo ecológico e cultural" na cidade (ETCHEVARNE, 2004a, p. 2). 
O edifício sede do Museu de História do Pantanal é o Wanderley, Baís \& Cia, construído em 1876 e considerado um dos principais pontos turísticos da cidade. Este prédio foi inicialmente, em 1876, uma casa comercial de propriedade de Firmo José de Mattos e com razão social de Firmo de Mattos \& Cia. E em seguida se tornou Firmo, Barros \& Cia., pois seu genro Antônio Pedro Alves de Barros se tornou sócio. "Em primeiro de julho de 1906, um novo contrato é realizado e com ele se forma a sociedade da empresa Wanderley, Baís \& Cia. [....] quando o sócio Antônio Pedro A. Barros se retira da sociedade e entra Francisco Bernardo Baís" (TARGAS, 2012, p. 61).

No primeiro momento o prédio foi destinado ao comércio local e em seguida uma casa de importação e exportação. No início do século XX, foi a maior casa de comercial do antigo estado do Mato Grosso, possuindo filiais em Aquidauana e Campo Grande. Durante muito tempo, o térreo do edifício abrigou a sede da $14^{\mathrm{a}}$ agência bancária do Banco do Brasil, quando havia cerca de 16 agências bancárias na cidade, sendo que grande parte era internacional. Em 1938 a Comissão Mista Ferroviária instalou sua sede no primeiro andar do prédio. Após o ano de 1960 a Casa Wanderley \& Baís ficou abandonada. Em 1992 foi tombada como Patrimônio Cultural Brasileiro pelo Instituto Patrimônio Histórico Artístico Nacional (IPHAN).

Com a utilização de equipamentos tecnológicos modernos, o Muhpan tenta contar a História da ocupação Humana na Região do Pantanal, seu enfoque está restrito a contar a história no território pantaneiro. O Pantanal está localizado no centro da América do Sul, com 250 mil km² de extensão, ao sul do Mato Grosso, ao nordeste do Mato Grosso do Sul, no território Brasileiro, além de passar por terras Paraguaias ao norte e terras Bolivianas ao leste. Essa história no Pantanal é narrada desde os primeiros ocupantes até a atualidade, para isso o Muhpan subdivide o tema geral "Ocupação Humana no Pantanal" em vinte e quatro subtemas (salas), tais como: Dez Pantanais, Arqueologia, Etnologia, Encontro das Civilizações, Conquista espanhola, Missões Jesuítas, Conquista portuguesa, Monções, Payaguás, Guaicurus, Tratados, Cidades e Fortes, Pintura Corporal, Expedição Científica, Estrada de Ferro Noroeste do Brasil, Primeiras Fazendas, Guerra do Paraguai, Os Pioneiros, Telegráfos, Comissão Rondon, Porto de Corumbá, Ladrilho Hidráulico, Pecuária e Olhares ao Pantanal. ETCHEVARNE, 2004a).

Um fator importante evidente dentro deste Museu é a Ação Educativa, que se faz coração pulsante do Muhpan sendo capaz de dar vida à exposição permanente do Museu e dialogar com seu visitante. A ação educativa do Muhpan trabalha com projetos, oficinas, atividades recreativas, aulas dinâmicas e entre outras atividades que tem a função de traduzir o conhecimento científico para um acesso a pessoas de diferentes faixas etárias e níveis de escolaridade, tornando o aprendizado fácil e atrativo.

A ação educativa em forma de projeto denominado "Memórias do Pantanal Rupestre" desenvolvido pelo Muhpan, merece destaque diante das várias ações desenvolvidas pela instituição, pois trabalhou com os Sítios Arqueológicos de Arte Rupestre. Cabe salientar que os Sítios Arqueológicos de Arte Rupestre são locais onde os indígenas ou algum povo anterior a eles, fizeram inscrições em cavernas, chão, paredes em forma de lascamento, incisões ou pinturas. O projeto desenvolvimento pelo Muhpan buscou um elo entre o conhecimento científico e a prática lúdica. Os participantes que pouco ou quase nada sabiam sobre arte rupestre ou petroglifos tiveram contato com a história arqueológica da região, como também puderam conhecer os sítios arqueológicos com as inscrições rupestres. Permitir que os participantes fossem a campo, foi capaz de sensibilizar o indivíduo mostrando a história do indígena e não a margem da história, mas sim como percussor. 
De acordo com dados obtidos junto ao Muhpan, observa-se que desde sua inauguração no ano de 2008 até o ano de $2014^{2}$, o Museu de História do Pantanal recebeu um quantitativo aproximado de 68.657 público-visitantes que pode ser observado em sequências anuais no gráfico 1.

\section{Gráfico 1- Quantitativo de visitação anual do Museu de História do Pantanal}

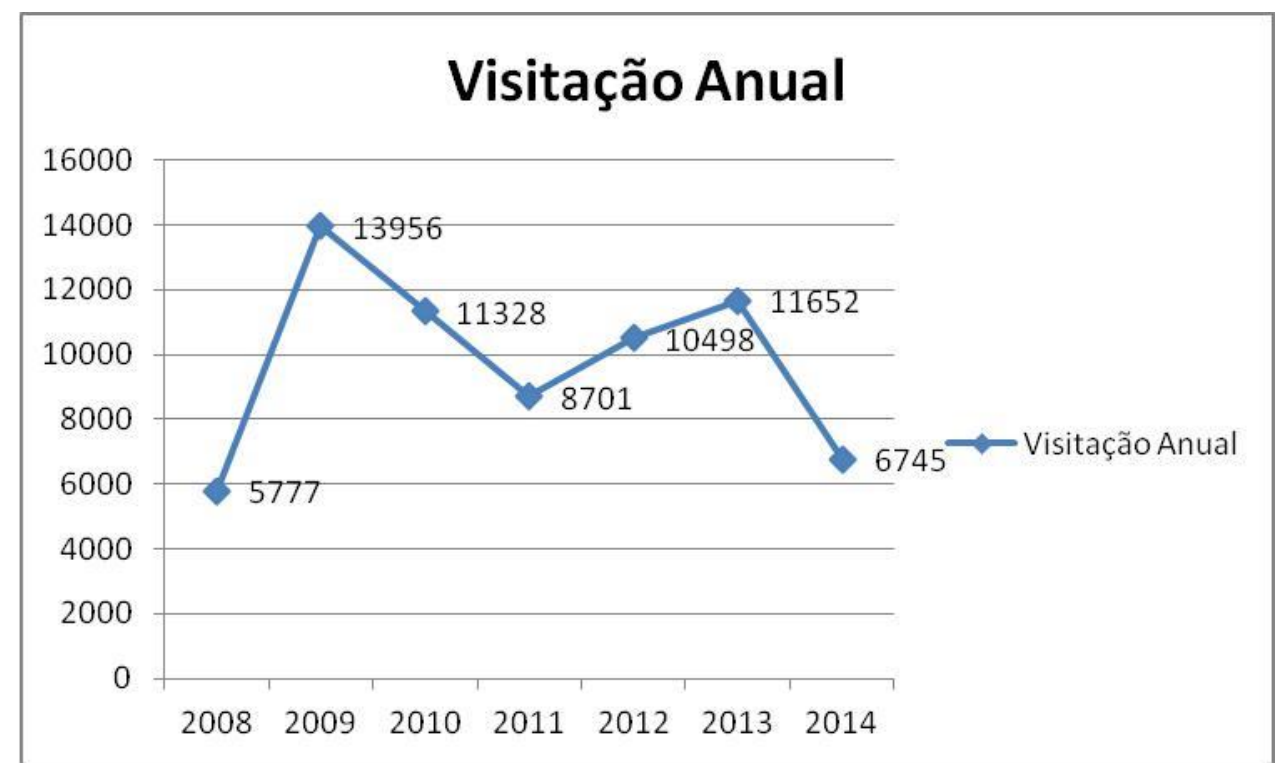

Fonte: Dados da pesquisa

Dentre esses 68.657 visitantes, podemos observar, mediante os dados fornecidos, que o público local é superior principalmente devido às visitas agendadas, visto que no Muhpan são priorizados os atendimentos voltados para grupos escolares. Por esse motivo, a ação educativa se tornou o coração pulsante da instituição.

\section{QUESTÕES INDÍGENAS DISPOSTAS EM SEIS SALAS DO MUHPAN}

O Circuito expositivo do Museu de História do Pantanal/Muhpan possui vinte e quatro subtemas (salas) e dentre esses, seis salas tratam sobre a temática indígena. Como se propõe contar a história da ocupação humana na região do Pantanal, a história indígena se inicia na Sala Arqueologia, na qual o visitante ao entrar se depara ao lado esquerdo, com um painel de representações das pinturas rupestre de cidades da região do Pantanal e do lado direito há uma simulação de um sítio arqueológico e um espaço destinado a uma simulação de escavação arqueológica.

Adentrando um pouco mais, pode-se perceber um painel denominado CaçadoresColetores, outro da Tradição Pantanal e o último da Tradição Descalvado. Ao meio destes painéis têm expositores de acrílico vedados, onde estão vasilhames cerâmicos reconstituídos, vestígios zoomorfos, vestígios de animais da mega fauna, além de painel em forma de réplica dos petroglifos. Nesta sala, conforme o projeto museográfico do Muhpan, produzido pelo historiador e arqueólogo baiano Carlos Etchevarne (2004a), a ocupação humana se deu no

\footnotetext{
${ }^{2}$ Até 2014 os dados fornecidos pela MUHPAN estavam mais organizados, por isso foram considerados até esse período.
} 
Pantanal aproximadamente entre 8.100 e 8.300 anos ap. quando se encontrou vestígios humanos, líticos de lascamento e polimento no Sítio MS-CP-22 localizado no município de Ladário (MS). Nesta sala também pode se encontrar um painel denominado caçador-coletor, onde fica claro para o visitante segundo a placa de identificação que esses caçadores-coletores são originários do período pleistoceno e que com o decorrer do tempo o indígena se sedentarizou no território Pantaneiro, adquirindo práticas na produção da cerâmica e de outros vestígios materiais. Ainda no primeiro painel temos cerâmicas da região do Pantanal Sul e no segundo painel há vestígios cerâmicos da Tradição Descalvado representativos da região do Pantanal Norte.

Na próxima sala Etnologia, pode ser observada uma vestimenta masculina Bororo, que expõe a imagem do indígena com as vestimentas tradicionais. Porém há um fato interessante que o educador, ao explicar essa vestimenta, apresenta o nome de cada acessório e diz que cada grupo indígena denomina suas vestimentas conforme sua cultura. Nesta sala também possui uma urna funerária que é apresentada como da Tradição Descalvado e como sendo um ritual importante e diferenciado em cada etnia. Em seguida possui um painel com nomes dos seguintes grupos indígenas: Bororo, Payaguás, Kinikinawa, Guató, Orejones, Xarayes, Caiapó, Kadiwéu e Guarani.

Segundo o relatório de Etchervarne (2004b), criador do roteiro do Muhpan, este painel expõe as representações mais significativos dos grupos indígenas durante o período do contato. Essas informações, segundo ele, foram baseadas na pesquisa realizada por Eremites e Viana (2000), no qual acrescenta que os grupos indígenas, no momento da conquista ibérica, possivelmente eram classificados levando em consideração a designação étnica, a área de ocupação e a filiação linguística. Muito provavelmente os mais conhecidos enquadrar-se-iam da seguinte maneira:

1) Chané e Guaná, Terena, Orejone e Xaray - Família linguística Arawak

2) Mbayá-Guaykuru, Payaguás e Agaz - Família linguística Guaikuru

3) Itatim e Guarambarense - Família linguística Tupi-Guarani

4) Kaingang - Família linguística Jê

5) Yshyr - Família linguística Zamuco

6) Guató - Tronco linguístico Macro-Jê

Esta sala era o espaço ideal para falar individualmente sobre as etnias indígenas, destaque que só é dado aos Guaicuru e Payaguás mais à frente na cronologia do museu. Ou seja, nesta sala somente expõe o nome dos indígenas e não há uma contextualização história. Esta sala deixar claro que haviam grupos diversificados no momento do encontro entre as civilizações, porém não se sabe de onde vieram, onde estão ou para onde foram. Sendo que ter acesso a essas informações são fundamentais, pois possuímos "[...] a necessidade de conhecer a diversidade cultural, étnica, histórica, linguística e antropológica dos povos indígenas do Brasil. [...]" (CALDERONI; MUSSI, 2014, p. 29). Desta forma, os indivíduos entenderão que existe diversidade entre os grupos indígena, ou seja, existe indígenas e não indígena.

$\mathrm{Na}$ Sala Conquista Espanhola possui dois painéis que falam sobre os percursos dos viajantes espanhóis até a chegada em Potosí com a descoberta das minas de Prata. Apresenta também em forma de imagens e relatos a visão etnocentrista que os viajantes descreviam os 
indígenas. Esta sala possui um conteúdo extenso e se assemelha com o transmitido por Costa (1999) em seu livro História de País inexistente: O Pantanal entre os séculos XVI e XVII.

Na sala seguinte, destinada as Missões Jesuítas podemos nos deparar com uma réplica em miniatura de uma Missão Jesuíta e um mapa histórico geográfico de La Província de Missiones 1585-1896, que apresenta as localizações das Missões Jesuítas do Itatin, Guayra e Tape. Com relação a conteúdo, se apresenta de forma resumida, dando destaque somente a Missão do Itatim devido a réplica já mencionada.

Na Sala Payaguá e Guaicuru há um quadro para cada etnia pintado pelo artista plástico paulista Filipelli e um texto que conta de forma sucinta as práticas dos Guaicuru e os Payaguá. No quadro fica bem explícito que os Payaguá eram dominadores da canoa e os Guaycuru do cavalo, não significando que ambos não tenham utilizado outros métodos de transporte. Com o destaque dado somente a essas duas etnias indígenas, esperava-se que fosse expresso mais conteúdos relevantes e contextualizados sobre os Payaguá e Guayrucu. Não ficou claro na exposição do museu ou no relatório do historiador que projetou a história do museu, os motivos pelos quais somente evidenciar esses dois grupos indígenas. Acredita-se que seja devido aos dados científicos que se apresenta maior sobre essas duas etnias.

$\mathrm{Na}$ última sala voltada para a temática indígena, denominada Pintura Corporal Bororo, pode ser observada um diorama da família Bororo, essa representação de família possui um tamanho semelhante ao de seres humanos, o que dá vida ao espaço. As réplicas de indígenas foram confeccionadas de isopor e ornamentado pelos próprios indígenas Bororo. Este diorama possui um dualismo, pois de um lado atrai a atenção dos visitantes, por possuir um tamanho semelhante e por apresentar as pinturas característica deste grupo, mas por outro lado desperta a imagem do indígena nu, com os corpos pintados, incivilizados, um primata, selvagem e preguiçoso.

$\mathrm{Na}$ análise realizada sobre a história indígena do Muhpan não foi observado que o Museu tem o propósito claro de fazer com que o visitante saia com a ideia de diversidade indígena ou que o indígena sofreu e sofre um processo de transformação na sua cultura. O Museu se preocupa mais em transmitir a história do todo e não das particularidades de cada processo histórico. O historiador que criou o projeto conceitual se atentou a contar 8,200 anos de história e acabou deixando lacunas que marcam até hoje a identidade dos indígenas do Pantanal representado pelo Museu de História do Pantanal.

Diante da temática indígena, narrada pelo Muhpan, não ficou explícito erros historiográficos, somente momentos de silenciamento e invisibilidade de momentos históricos importantes. Sabemos que o indígena possui identidades estereotipadas e preconceituosas que advém do período colonial, mas que ainda se encontram vivas na sociedade. Os museus enquanto instituições de ensino e pesquisa não devem estimular o preconceito, mas sim abrir a mente dos visitantes apresentando diversidade e transformação na cultura indígena. Pois desta forma o indivíduo será capaz de refletir criticamente sobre a história indígena, principalmente os professores de história, que trabalham com esses conteúdos dentro da ementa escolar.

O Museu de História do Pantanal deve ser visto como um portador de estratégias discursivas, que é transmissor de um conhecimento geral e não aprofundado da história indígena. Deve ficar claro, que este espaço não possui um conteúdo completo sobre a questão indígena, mas o conhecimento transmitido no museu é capaz de ser base para a construção de outros. Ou seja, não significa que o professor não deva visitar o Museu, pelo contrário, o Muhpan transpira conhecimento e contribui na transmissão de valores. É preciso um professor orientador, que dirija a visita e não aquele que se deixa ser dirigido pelo discurso do narrador. 


\section{PRÁTICA SOBRE A QUESTÃO INDÍGENA}

No ano de 2016, um grupo de alunos do ensino fundamental de uma escola particular da cidade de Corumbá/MS realizaram visita ao Museu de História do Pantanal. Com isso, foi solicitado que todos os alunos realizassem um desenho no final da visita. O desenho deveria representar o indígena ou sua cultura. Houve o retorno de 27 (vinte e sete) desenhos, dentre os quais foram selecionados 3 (três) imagens que mais representavam os demais, conforme apresentados nos Quadros 1, 2 e 3. Cabe salientar que os nomes dos alunos são fictícios para manter em sigilo as suas identidades.

\section{Quadro 1- Visão de Indígena do aluno Armando de 10 anos.}

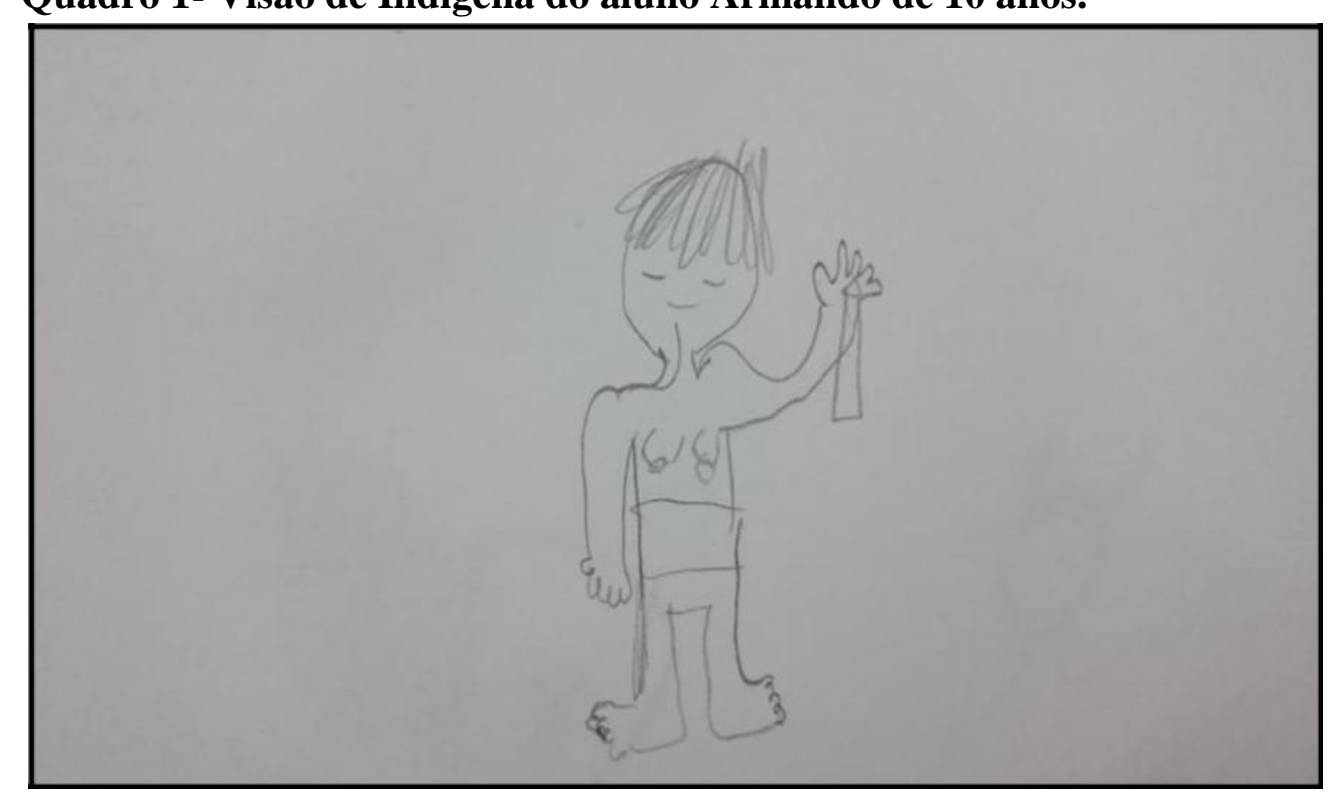

Fonte: Dados da pesquisa

Quadro 2 - Visão de Indígena do aluno Eder de 10 anos.

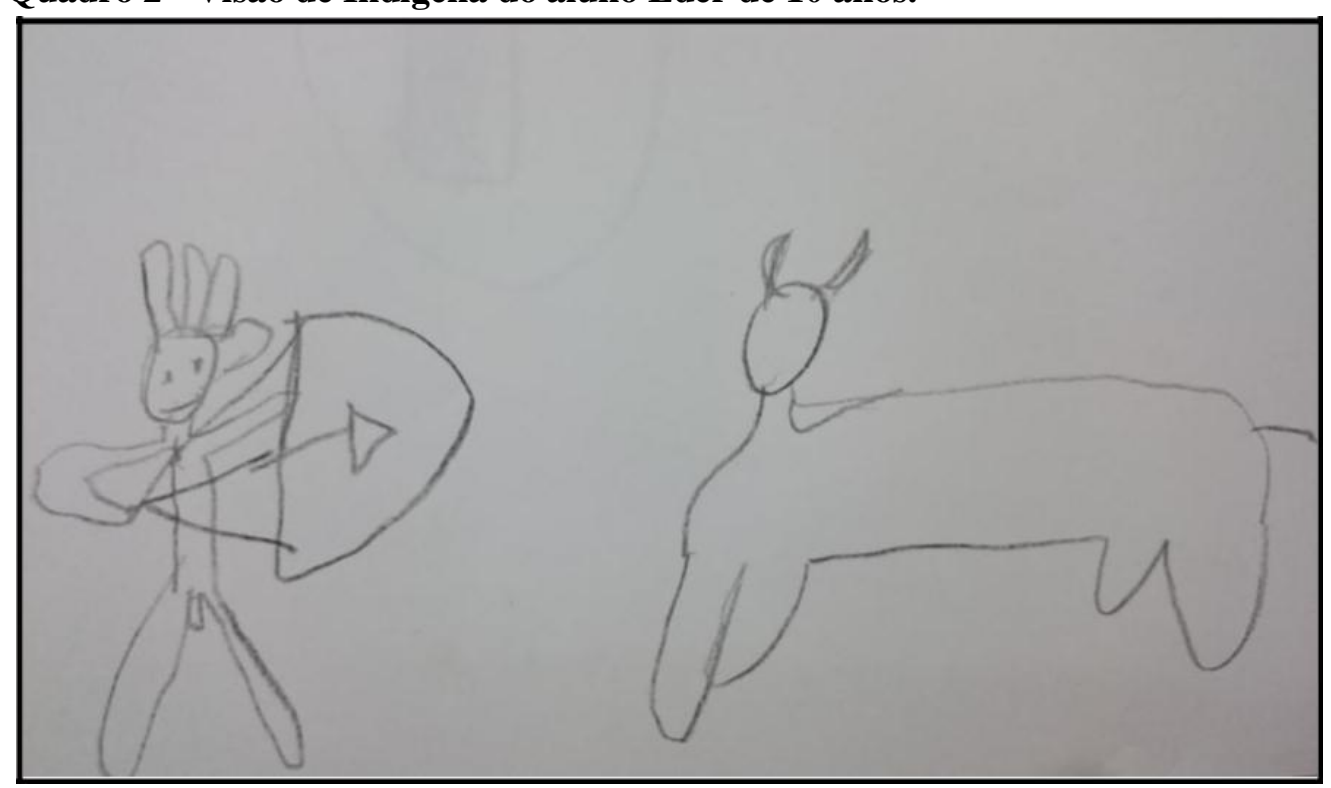

Fonte: Dados da pesquisa 


\section{Quadro 3 - Visão de Indígena do aluno Enzo de 11 anos}

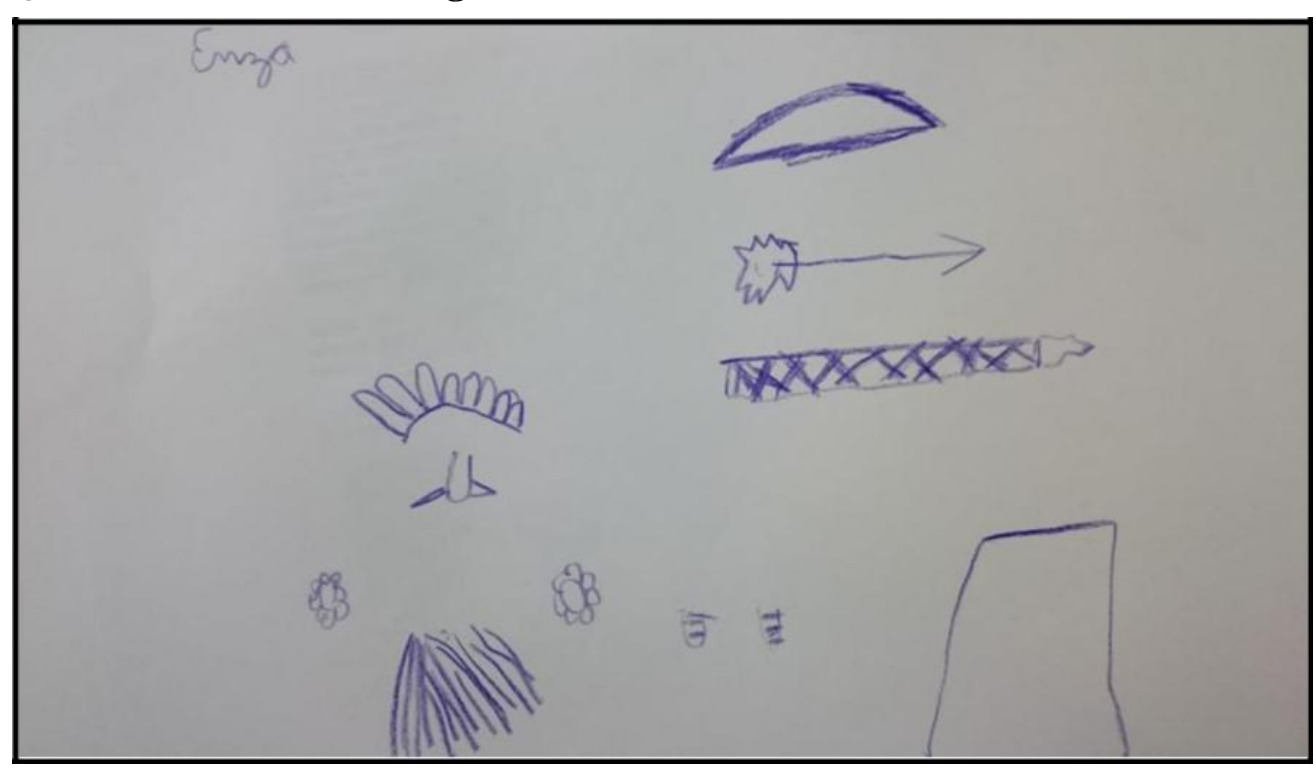

Fonte: Dados da pesquisa

Analisando os três desenhos realizados após a visita, podemos perceber que as representações dos alunos estão carregadas de estereótipos, visto que os desenhos evidenciam que a imagem do bom selvagem ainda está presente no imaginário dos estudantes. Assim, no quadro 1 aparece a indígena que está com os seios de fora, sugerindo que a cultura do índio é caracterizada pela nudez; no Quadro 2 o indígena é sinônimo de caçador selvagem, por estar mirando um animal; no Quadro 3 predomina a ideia de que se trata de uma cultura em atraso, caracterizada pela vestimenta e adorno dos indígenas.

Por meio desses desenhos, observamos um indígena genérico e universal, estigmas que os alunos carregam que são originários de seus pais, colegas, professores etc. Para mudar essa realidade, Calderoni e Mussi (2014, p. 42) nos alertam que é preciso realizar um “[...] processo de desconstrução, num exercício de descolonização dos equívocos geradores de preconceitos que seguem sendo reproduzidos historicamente em diversos espaços educativos, incluindo-se os artefatos culturais que transitam na escola". Segundo as autoras, essas diferenças coloniais faz com que os indígenas permaneçam à margem da sociedade, mesmo reconhecendo que não existe superioridade entre a cultura do branco ou indígena. Na realidade, o que predomina no Brasil é uma grande diversidade cultural, a qual não deve ser entendida como desigualdade, ou segundo a perspectiva da relação inferioridade $\mathrm{x}$ superioridade, devendo haver o respeito $\mathrm{e}$ valorização das diferenças culturais, que juntas representam a nação. No caso dos indígenas, é preciso considerar que:

[...] a participação do índio foi e continua sendo enorme: na formação do povo brasileiro (oficialmente na junção de três raças: a indígena, a branca e a negra; ainda que saibamos que o seguimento branco foi o dominante, a cujo projeto colonizador submeteu o índio e o negro), na agricultura familiar, na conservação do meio ambiente, na defesa do território, na língua portuguesa, nas artes, na medicina tradicional, na educação; enfim, em muitas áreas do conhecimento teórico e prático. (CALDERONI; MUSSI, 2014, p. 45)

Diante do que foi apresentada sobre a cultura indígena exposta no Museu de História do Pantanal, bem como por meio da análise dos desenhos dos alunos, percebemos que na temática 
indígena narrada pelo referido museu não ficou explícito erros historiográficos, mas sim há um silenciamento e invisibilidade de períodos históricos importantes das diversas culturas indígenas. Para tentar sanar tais limitações, as práticas educativas existentes no Muhpan tentam contar histórias que não estão presentes no circuito expositivo. Ainda assim, percebemos, pelo desenho das crianças, que há lacunas da história das diversas culturas indígenas presentes no Pantanal, representadas pelo Muhpan.

\section{CONSIDERAÇÕES FINAIS}

O Museu de História do Pantanal/Muhpan utiliza-se de recursos tecnológicos, que o diferencia dos demais museus, em sua narrativa sobre a história da ocupação humana na região do Pantanal. Porém, ao ousar contar a história de aproximadamente 8,200 anos, o referido museu apresenta algumas lacunas, por não contemplar as diferentes culturas locais. Quando se analisa o circuito expositivo do Muhpan, percebemos que não há a preocupação em expor especificamente sobre a história do indígena, do negro, da arqueologia e do Pantanal, mas sim um contexto histórico mais amplo.

Nesse sentido, em relação à história dos indígenas, consideramos que se trata de um aspecto que deve ser revisto, uma vez que esse grupo étnico costuma ser lembrado apenas como primeiro ocupante da terra, deixando de retratar as fases posteriores. Com o Muhpan não foi diferente, tendo em vista que a presença indígena encontra-se exposta apenas no primeiro pavimento, sem contemplar os demais grupos étnicos, que historicamente contribuíram para a construção da região do Pantanal.

No segundo pavimento do Muhpan, se observa que existem exposições sobre a guerra do Paraguai, o Porto de Corumbá, os imigrantes, mas sem nenhuma relação com os indígenas, o que não significa, porém que eles não tenham feito parte da história, ou que a sua contribuição tenha sido insignificante. Na realidade, evidencia-se que a variedade de cultura indígena existente na região do Pantanal não foi considerada relevante para ser retratada no museu e, por esse motivo, o indígena só aparece no período colonial (primeiro pavimento) e sua cultura se efetiva com traços desse contexto histórico. Como consequência de tal organização, o visitante sai com a ideia de que o indígena vive nu, com pinturas no corpo, com arco e flecha, pois é essa imagem retratada pelo Muhpan, não representando, portanto o indígena da sociedade atual.

Com relação ao conteúdo no contexto indígena, não foi percebido nenhum equívoco histórico grave, mas sim situações de silenciamento. Não se observa na história das etnias, maiores informações relativas para onde foram ou se elas ainda existem. Ou seja, embora existindo cinco salas que abordam sobre os indígenas no Muhpan, a retratação se dá de forma geral, sem especificar a variedade cultural, pelo fato de o referido museu apresentar, em seu circuito expositivo, um longo período histórico.

Por meio do estudo realizado, percebemos que, segundo a concepção histórica de museu, o Muhpan se caracteriza pela visão atualizada, entendida como museu vivo, que estimula a visitação e propõe atividades educativas diferenciadas. Nesse cenário, não se percebe grandes problemas, pois o museu se caracteriza por sua forma dinâmica. Em relação às diferentes culturas indígenas, presentes historicamente na região do Pantanal, embora existindo a omissão de muitas delas, por meio das atividades de ensino desenvolvidas pelo Muhpan, torna-se possível minimizar essas lacunas. Assim, a diversidade cultural indígena presentes na região pantaneira, se mantém como conteúdo relevante, sendo transmitida aos visitantes, por meio das ações educativas e do trabalho realizado pelos mediadores que atuam profissionalmente no Museu de História do Pantanal. 


\section{Referências}

ALABARSE, P. P. Visita ao museu de ciências: uma análise das relações que se estabelecem entre o visitante, o monitor e o objeto da exposição. 2011. iv, 110 f., il. Dissertação (Mestrado em Educação) - Universidade de Brasília, Brasília, 2011.

ANDERSON, D.; KISIEL, J.; STORKSDIECK, M. Understanding Teachers' Perspectives on Field Trips: Discovering Common Ground in Three Countries. Curator: The Museum Journal, v. 49, n.3, p.365, 2006.

CALDERONI, V. A. M. O.; MUSSI, V. P. L. Culturas e história dos Povos indígenas: Desconstruindo preconceitos sobre os povos indígenas. Campo Grande: EAD/ UFMS, 2014.

CARLAN, C. U. Os museus e o patrimônio histórico: uma relação complexa. História Franca, v. 27, n. 2. 2009.

CAVALCANTI, L. Modernistas na repartição. Rio de Janeiro: Editora UFRJ, 2000.

CAZELLI, S.; MARANDINO, M.; STUDART, D. Educação e Comunicação em Museus de Ciência: aspectos históricos, pesquisa e prática. In: Educação e Museu: a construção social do caráter educativo dos museus de ciência. Rio de Janeiro: Access, 2003. p. 83-106.

COSTA, M. F. A História de um país inexistente: Pantanal entre os séculos XVI e XVIII. São Paulo: Estação Liberdade Kosmos, 1999.

ETCHEVARNE, C. Projeto expográfico do Museu de História do Pantanal. Corumbá: Muhpan, 2004a.

ETCHERVANE, C. História da Ocupação Humana do Pantanal Matogrossense. Programa Monumenta - MINC - Museu de História do Pantanal, 2004b.

EREMITES, J.; VIANA, S. A. O Centro-Oeste antes de Cabral. Revista USP, São Paulo, n.44, p.142-89, 2000.

JULIÃO, L. Apontamentos sobre a história do Museu. Belo Horizonte: Secretaria de Estado da Cultura/Superintendência de Museus. Caderno de Diretrizes Museológicas, 2011.

MASSARANI, L. (Org). Diálogos \& ciência: mediação em museus e centros de Ciência. Rio de Janeiro: Museu da Vida/ Casa de Oswaldo Cruz/ Fiocruz, 2007.

MARANDINO, M. Museus de Ciências como Espaços de Educação In: MARANDINO, M.(Org.) Museus: dos Gabinetes de Curiosidades à Museologia Moderna. Belo Horizonte: Argumentum, 2005, p. 165-176.

MARTINS, E. B. C. O serviço social na área da educação. Serviço Social e Realidade, n.1, v,8, p 57-73, 1999.

MORAES, R.; BERTOLETTI, J. J.; BERTOLETTI, A. C.; ALMEIDA, L. S. Mediação em museus e centros de ciências: O caso do Museus de Ciências e Tecnologia da PUCRS. In: 
MASSARANI, L.; RODARI, P.; MERZAGORA, M. Diálogos e Ciência: mediação em museus e centros de ciência. Rio de Janeiro: Fiocruz, 2007, p. 55-66.

SILVA, A. T. Uma Análise das práticas do Museu Oceanográfico Professor Eliézer de Carvalho Rios e Centros Associados, Rio Grande-RS. Monografia. Universidade Federal de Pelotas, Rio Grande do Sul, Brasil, 2011.

STUDART, D. C. Reflexões sobre o papel educativo e comunicativo dos museus e sobre o trabalho do CECA- Brasil. In: A comunicação em questão: exposição e educação, propostas e compromissos. São Paulo: MAE/USP, 2003. p. 137-150.

TARGAS, Z. I. M. S. As casas comerciais importadoras/expotadoras de Corumbá (19041915). 2012. 103 f. Tese (Mestrado em História)- Faculdade de Ciências Humanas da Universidade Federal da Grande Dourados (UFGD), Dourados. 2012.

VAN-PRÄET, M.; POUCET, B. Les Musées, Lieux de Contre-Éducation et de Partenariat Avec L'École, Education \& Pédagogies - dés élèves au musée, n. 16, Centre International D’Études Pédagogiques, 1989. 